\title{
Form Recognition dan Character Mapping Menggunakan Image Segmentation dan Optical Character Recognition
}

\author{
http://dx.doi.org/10.28932/jutisi.v7i1.3340 \\ Riwayat Artikel \\ Received: 27 Januari 2021 | Final Revision: 20 Maret 2021 | Accepted: 22 Maret 2021 \\ Christian Wibisono ${ }^{\# 1}$, Setia Budi ${ }^{\bowtie \# 2}$ \\ \# Jurusan Magister Ilmu Komputer, Universitas Kristen Maranatha \\ Jl. Surya Sumantri no. 65, Sukawarna \\ ${ }^{1} 1979002 @$ maranatha.ac.id \\ ${ }^{2}$ Setia.Budi@it.maranatha.edu
}

\begin{abstract}
Industry 4.0 revolves around the way of thinking in the manufacturing factory business. Speed and accuracy become the main focus to survive and grow in an uncertain situation. This study aims to build a system blueprint that will increase both speed and accuracy to input from data. This research uses several computer vision technologies like Convolutional Neural Network (CNN) that is used to do form classification and image segmentation, there is also Optical Character Recognition (OCR) which extracts specific information from a document that has been classified with CNN and then transforms it into a JSON format which has more generic format and can be used in most common platform.
\end{abstract}

Keywords-CNN; Form; OCR; Recognition

\section{PENDAhUluan}

Seiring dengan perkembangan teknologi yang semakin maju, maka setiap perusahaan textile dituntut untuk ikut berkembang agar bisa bertahan. Khususnya di era industri 4.0 di mana sudah dituntut untuk menerapkan smart factory. Hal ini menjadi perhatian khusus untuk melakukan studi yang bisa mendukung kelangsungan sebuah perusahaan textile.

Permasalahan yang umum dihadapi perusahaan textile biasanya berkaitan dengan performa kecepatan mengelola suatu task ataupun akurasi yang dihasilkan dari sebuah action. Kecepatan yang rendah berpotensi untuk meningkatkan kerugian dikarenakan efisiensi yang tidak sepadan dengan labour cost yang ada, meskipun pekerjaan yang dikerjakan benar hal ini tidak menjamin profit jika tidak diselaraskan dengan kecepatan kerja yang tinggi [9]. Di sisi lain akurasi memiliki peranan penting yang dapat menentukan keberlangsungan suatu perusahaan textile. Keakuratan data menjadi sebuah keharusan untuk perusahaan textile bisa mencapai profit yang baik, Data merupakan landasan pokok yang membangun sebuah sistem [9]. Tidak peduli sebaik apapun sebuah sistem yang diimplementasikan, jika data yang ada tidak akurat maka output yang dihasilkan juga tidak akan akurat. Kondisi ini bisa menyebabkan sebuah perusahaan mengalami kerugian bahkan kebangkrutan jika sampai salah mengambil keputusan yang diakibatkan kondisi data yang tidak akurat Pada studi yang dilakukan pada salah satu perusahaan textile, kecepatan yang rendah mengakibatkan tingkat delay pengiriman barang cukup tinggi yang mana hal ini bisa mengakibatkan citra perusahaan terkait menjadi buruk di depan pelanggan. Sedangkan Tingkat akurasi yang rendah mengakibatkan kesalahan perhitungan costing yang mengakibatkan perusahaan merugi saat menentukan harga jual.

Untuk menjawab kebutuhan perusahaan textile terkait dalam meningkatkan kecepatan dan akurasi, Maka perlu dilakukan perubahan cara kerja dalam memperlakukan penginputan data ke dalam sebuah sistem. Data yang umum dilakukan input pada perusahaan ini pada umumnya berupa form supplier, di mana perusahaan ini memiliki banyak supplier yang memiliki form transaksi beragam sehingga tingkat kerumitan yang ada cukup kompleks. Form sendiri dapat diartikan sebagai informasi yang biasanya dipindahkan dari sebuah media cetak ke dalam sistem yang digunakan. Proses input ini memakan waktu yang cukup banyak dikarenakan kecepatan dari setiap orang yang mengerjakan berbeda, akurasi yang dihasilkan juga akan rentan terhadap kesalahan input yang berpotensi menyebabkan kerugian terhadap perusahaan.

Untuk mempercepat proses input form. Maka diperlukan sebuah sistem yang mampu meningkatkan kecepatan melakukan input form, namun juga harus meningkatkan akurasi data secara keseluruhan. Untuk memenuhi 
kebutuhan ini maka studi ini dilaksanakan untuk membuat blueprint sistem yang nantinya bisa digunakan oleh perusahaan untuk mengembangkan sistem untuk menyesuaikan dengan proses bisnis yang ada secara internal. Di harapkan hasil dari studi ini mampu meningkatkan kecepatan input sehingga image perusahaan tetap baik di hadapan pelanggan, di satu sisi akurasi yang meningkat diharapkan bisa membantu perusahaan dalam proses costing agar penentuan harga jual bisa menghasilkan profit.

Sistem yang dibuat memiliki fungsi untuk melakukan pengelompokan form dan scanning form. Untuk pengelompokan form akan menggunakan arsitektur $C N N$, arsitekrur ini merupakan salah satu komponen dalam computer vision yang memiliki fungsi untuk menghasilkan model yang mampu mengelompokan sebuah image berdasarkan konten visual yang dimilikinya [2]. Sedangkan untuk scanning form akan digunakan arsitektur $O C R, O C R$ sendiri merupakan salah satu arsitektur yang ada di dalam computer vision yang memiliki fungsi untuk menerjemahkan setiap informasi alphabetic yang ada di dalam sebuah image ke dalam format ASCII [1]. Nantinya hasil format ASCII ini akan dilakukan transformasi ke dalam bentuk JSON, agar bisa digunakan pada platform aplikasi secara global.

Dengan adanya sistem ini, pengguna tidak perlu lagi memindahkan informasi yang ada ke dalam aplikasi. Namun hanya perlu melakukan review dari hasil pengelompokan dan scanning yang dikerjakan oleh sistem. Dengan demikian kecepatan akan meningkat dikarenakan campur tangan end user berkurang drastis dalam melakukan proses input dan akurasi akan meningkat dikarenakan pengecekan yang dilakukan oleh sistem ini memiliki tingkat error yang lebih kecil dibandingkan pengecekan yang dilakukan oleh user.

Dengan Kebutuhan yang harus dipenuhi oleh perusahaan terkait maka didapat rumusan masalah yang menjadi fokus untuk meningkatkan efektifitas penggunaan waktu dan akurasi data. Apakah sistem yang mampu meningkatkan kecepatan dan akurasi dalam melakukan penginputan form supplier, sehingga delay pengiriman barang bisa dikurangi dan akurasi costing produk lebih akurat.

Pada penelitian ini ada beberapa batasan yang diterapkan di mana batasan ini dimaksudkan agar penelitian terkait bisa lebih fokus pada permasalahan pokok. Adapun batasan yang dimaksud berkaitan dengan form yang discan harus diisi secara digital tidak ditulis tangan. Dan dataset yang digunakan pada studi ini bersifat public dan tidak mengandung data rahasia ataupun informasi sensitif yang bisa merugikan pihak lain.

Tujuan dari studi ini adalah untuk menciptakan sebuah sistem, yang mampu menunjang proses input data form yang sebelumnya dilakukan sepenuhnya oleh staff administrasi. sistem akan otomatis mengelompokan form sesuai kategorinya lalu melakukan scanning dokumen untuk mendapat value yang akan dipindahkan. Dengan sistem ini staff administrasi yang sebelumnya melakukan input data akan beralih fungsi menjadi pihak yang melakukan verifikasi kesesuaian data yang dihasilkan secara automatis oleh sistem. Sistem yang dibuat pada penelitian ini bukanlah produk final yang bisa langsung digunakan oleh perusahaan. Sehingga perlu dilakukan tuning untuk menyesuaikan kebutuhan proses bisnis yang ada sebelum bisa digunakan pada sistem utama.

\section{LANDASAN TEORI}

Pada bagian ini akan dibahas teori - teori yang berhubungan dengan Convolutional Neural Network (CNN) dan Optical Character Recognition (OCR).

\section{A. Convolutional Neural Network (CNN)}

$C N N$ merupakan salah satu arsitektur dalam ilmu deep learning, CNN sendiri merupakan sebuah metode yang memiliki fungsi untuk mengenali objek berupa data digital. Dengan menerapkan $C N N$, hal ini memungkinkan sebuah device komputer untuk mengenali objek tertentu yang tersimpan dalam image. Contoh saat image yang berisi gambar manusia dibaca oleh komputer, komputer akan melihat model yang sudah ada lalu mengidentifikasi gambar tersebut dan menghasilkan output bahwa gambar tersebut adalah manusia. Jika digambarkan secara sederhana, cara kerja ini sama seperti mata manusia yang bisa mengenali objek yang berada dalam suatu gambar atau lukisan.

CNN sendiri merupakan arsitektur yang dikembangkan dari Multilayer Perception (MP) yang memiliki kegunaan untuk mengolah data gambar dua dimensi. Secara garis besar arsitektur $C N N$ memiliki 3 layer dan 2 bagian utama. Untuk layer yaitu convolutional layer, Pooling layer, dan fully-connected layer. Sedangkan untuk bagian utama terdiri dari Feature Learning dan classification yang bisa dilihat pada Gambar 1. Metode ini yang nanti akan digunakan untuk mengenali suatu form berdasarkan label yang sudah diberikan. Berikutnya akan dibahas mengenai kegunaan dari masing - masing layer.

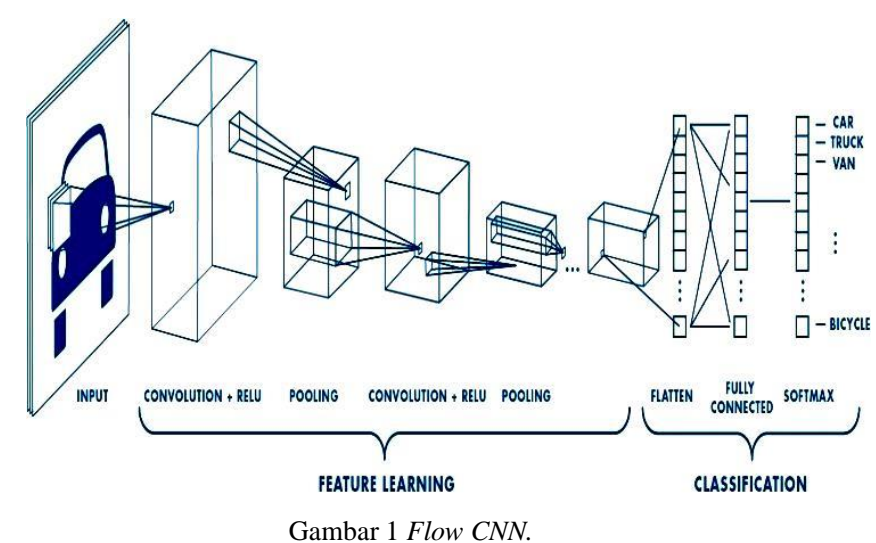

Dari gambaran umum mengenai $C N N$ yang sudah dibahas selanjutnya akan dibahas mengenai convolutional 
layer. Convolutional layer Merupakan sebuah layer yang digunakan untuk memindai gambar digital, untuk convolutional layer sendiri memiliki neuron yang berupa matriks tiga dimensi yang terdiri dari panjang, lebar, dan tebal [3]. Untuk penentuan panjang, lebar dan tebal tergantung dari image yang dipindah semakin besar ukuran pixel gambar maka akan semakin besar ukuran matriks 3 dimensi dari neuron yang ada. Tujuan dari neuron ini adalah untuk mengambil sebagian value dari image lalu neuron yang sudah menangkap nilai citra ini dilakukan operasi dot matrix dengan filter yang digunakan pada convolutional layer. Untuk hasilnya setiap hasil perkalian dot matrix tersebut akan menghasilkan output yang memiliki istilah sebagai activation map.

Hasil perhitungan dari convolutional layer ini nantinya akan diproses oleh Pooling layer. Pooling layer memiliki fungsi untuk mereduksi dimensi matrix dari output yang dihasilkan oleh Convolutional layer. Untuk operasi reduksi teknik yang digunakan adalah downsampling adapun metode yang digunakan adalah max pooling. Di mana teknik ini akan mengambil nilai terbesar dari dari masing - masing level layer yang ada seperti Gambar 2 [3]. Adapun untuk hasil output dari pooling layer ini akan digunakan pada Convolutional layer di tahap selanjutnya, hal ini akan terus dilakukan sampai semua informasi didapat dengan nilai error yang kecil.

\begin{tabular}{|c|c|c|c|}
\hline 12 & 20 & 30 & 0 \\
\hline 8 & 12 & 2 & 0 \\
\hline 34 & 70 & 37 & 4 \\
\hline 112 & 100 & 25 & 12 \\
\hline
\end{tabular}$\stackrel{2 \times 2 \text { Max-Pool }}{\longrightarrow}$\begin{tabular}{|c|c|c|}
\hline 20 & 30 \\
\hline 112 & 37 \\
\hline
\end{tabular}

Gambar 2 Max Pooling.

Hasil dari pooling layer ini nantinya akan diproses pada fully-connected. Fully-connected merupakan layer terakhir dari tahap $C N N$ di mana tugas dari layer ini adalah membentuk data yang sebelumnya sudah dipecah-pecah pada layer sebelumnya [6].

\section{A. Optical Character Recognition}

OCR merupakan sebuah fungsi yang berguna untuk menerjemahkan text yang ada di dalam image menjadi hasil output dalam bentuk ASCII text [2]. Keunikan dari OCR ini sendiri adalah fungsi ini mampu membedakan antara icon, image, dan text di dalam citra digital. Sehingga hasil output hanya menghasilkan text saja. Adapun struktur pemrosesan dari image menjadi text dalam OCR memiliki beberapa tahap yang terdiri dari Preprocessing, segmentation, extraction, classification dan post processing yang dapat dilihat pada Gambar 3.

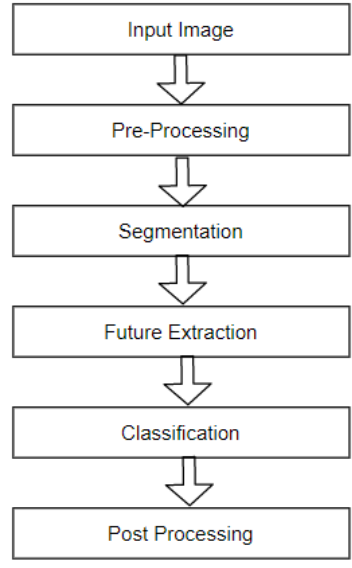

Gambar 3 Pemodelan $O C R$.

Adapun pada tahap Preprocessing yang dilakukan adalah merubah semua image di dalam dataset yang sebelumnya memiliki warna menjadi gray image lalu sesudah itu akan di convert menjadi binary data [8]. Jika sudah maka tahapan selanjutnya adalah melakukan reduksi noise yang ada misalnya gaussian noise.

Tahapan berikutnya adalah melakukan segmentasi, di mana setiap data binary yang sudah dibersihkan akan dilakukan proses pemecahan data. Di mana setiap huruf akan dibuat ke dalam bentuk biner, dalam melakukan proses ini $O C R$ akan mengetahui mana data yang merupakan character dan mana data yang bukan merupakan character [8]. Sesudah tahapan ini maka langkah selanjutnya yang dilakukan adalah feature extraction, di mana jika ditemukan intersection diantara binary maka OCR akan menggabungkan huruf-huruf tersebut menjadi kata. Hal ini akan berulang kali dilakukan hingga menjadi 1 paragraf dan menyelesaikan seluruh image atau document yang di scan.

Langkah terakhir adalah classification, di mana dari setiap paragraf yang terbentuk $O C R$ akan memberikan label, sehingga saat proses rekonstruksi $O C R$ tidak akan keliru mengambil value selain character [8]. Jika sudah tahapan selanjutnya adalah post processing di sini terkait dengan mengolah hasil output dari $O C R$, bisa juga mengolah kembali dataset agar proses pembacaan $O C R$ menjadi lebih cepat.

Adapun juga digunakan beberapa library yang merupakan pendukung agar arsitektur $O C R$ dapat digunakan dengan baik, library ini adalah pytesseract dan OpenCV. Pytesseract merupakan library yang menerapkan algoritma dari $O C R$, pytesseract sendiri digunakan untuk mendeteksi object berupa character dari suatu gambar, dan menerjemahkannya ke dalam bentuk string [7]. Sedangkan OpenCV merupakan salah satu library python yang berhubungan dengan pengelolaan object detection, modul yang akan digunakan dari library OpenCV adalah object detection di mana OpenCV mampu mengenali setiap object yang ada di dalam gambar [7]. 


\section{B. Penelitian terkait}

Penerapan $C N N$ dan $O C R$ untuk melakukan klasifikasi dan recognition sudah pernah dilakukan oleh penelitian penelitian yang ada. Setiap penelitian yang dilakukan memiliki metode tersendiri yang sudah disesuaikan dengan dataset yang ada. Pada penerapan CNN setiap penelitian memiliki setup parameter global yang berbeda dan penerapan beberapa teknik turunan yang ditambahkan, Untuk OCR sendiri penelitian yang ada berfokus pada cara melakukan segmentasi karakter.

Diego R Faria dan kawan - kawan menggunakan dataset CIFAR untuk melakukan klasifikasi image dengan format RGB yang tidak memiliki sub direktori dengan menggunakan arsitektur Inception V3 dan menggunakan pendekatan transfer learning untuk proses pembuatan modelnya [3]. Pada penelitian ini tidak dilakukan proses preprocessing untuk menyesuaikan dengan model yang digunakan pada transfer learning, sebelum melakukan proses training Diego R Faria melakukan pengelompokan image yang didasarkan pada area label yang menunjukan identitas unik sebuah image. Dari proses ini didapat tiga kategori utama yaitu image human, car, dan animal, pada kategori human dilakukan percobaan menggunakan 500 epoch dengan 4000 epoch untuk mengetahui pengaruh epoch terhadap sebuah image yang memiliki kompleksitas tinggi tanpa adanya preprocessing yang hasilnya bisa dilihat pada Gambar 4. Untuk kategori car dan animal Diego R Faria hanya menggunakan 500 epoch dikarenakan percobaan pada kategori human sudah memberikan hasil bahwa epoch mempengaruhi tingkat akurasi suatu model [3].

\begin{tabular}{|c|c|}
\hline Accuracy for 500 epochs & Accuracy for 4000 epochs \\
\hline $88 \%$ & $95 \%$ \\
\hline
\end{tabular}

Gambar 4 Pengaruh epoch percobaan Diego R Faria.

Liu Liu dan kawan - kawan menggunakan dataset yang dibangun sendiri dan diberikan label dengan menerapkan bounding box, dataset yang dibangun oleh Liu Liu terdiri dari 1500 gambar dengan format grayscale yang dibagi menjadi 2 kategori berbeda dan tidak dilakukan preprocessing apapun sebelum dilakukan training model [13]. Proses pembentukan model dibangun menggunakan arsitektur $C N N-A G G$ di mana arsitektur ini menjalankan clustering $C N N$ yang hasilnya akan disambungkan secara seri. Adapun model variabel yang ditentukan pada penelitian ini menggunakan 20 epochs. Model yang dihasilkan memiliki tingkat akurasi sebesar $83 \%$ dengan data loss sebanyak $0.42 \%$.

Manohar Karki dan kawan - kawan menggunakan dataset MINST untuk melakukan proses klasifikasi character bangla dan proses perbaikan kernel sebelum dilakukan document scanning, sebelum dilakukan proses training dataset yang ada dilakukan proses preprocessing seperti gausian noise untuk menghilangkan noise yang ada di dalam image [12]. Pada proses klasifikasi Manohar Karki menggunakan transfer learning dengan arsitektur CNN ImageNet, model yang dihasilkan memiliki fungsi untuk membedakan dokumen yang memiliki karakter bangla dengan akurasi sebesar $95 \%$ dan data loss sebesar $0.30 \%$. Selanjutnya dilakukan proses document scanning dan perbaikan kernel dengan menerapkan CRN. CRN akan melakukan rekonstruksi setiap pixel character hingga didapat nilai motion yang stabil. Akurasi pembacaan sebelum dilakukan rekonstruksi adalah 80\% sedangkan akurasi pembacaan setelah dilakukan rekonstruksi adalah $87 \%$.

Sukhvinder Singh dan kawan - kawan menggunakan dataset yang dibuat sendiri untuk melakukan proses dokumen scanning [14]. Dataset yang ada dibagi ke dalam 3 kategori di mana dipisahkan berdasarkan ukuran dari text yang ada di dalam gambar. Kategori pertama di isi gambar dengan ukuran text kecil, kategori kedua di isi dengan text ukuran sedang dan kategori ketiga di isi dengan text ukuran besar. Dari setiap kategori Sukhvinder Singh melakukan morphologi matematis untuk mengambil setiap karakter alphabet yang ada dan melakukan preprocessing untuk menghilangkan noise berupa garis tepi. Setelah itu dilakukan proses penggabungan semua kategori ke dalam satu direktori yang sama lalu dilakukan document scanning. Dari penelitian ini didapat informasi bahwa perbesaran pixel dan penghilangan garis tepi bisa meningkatkan akurasi pembacaan OCR. Akurasi sebelum dilakukan proses morphologi untuk kategori gabungan sebesar $79.31 \%$ sedangkan setelah dilakukan proses morphologi akurasi yang dihasilkan sebesar $82.15 \%$ [14].

Rifiana Arief dan kawan - kawan menggunakan dataset yang dibuat sendiri untuk melakukan document scanning. Dataset ini terdiri dari sekumpulan gambar yang memiliki resolusi dan pixel yang besar, penelitian ini dijalankan pada environment hadoop sehingga memungkinkan clustering untuk mempercepat proses scanning document [15]. Dataset yang ada tidak dilakukan proses preprocessing dan penerapan $O C R$ pada penelitian ini menggunakan 3 tools yang berbeda. Tujuan dari penelitian ini adalah untuk mendapatkan akurasi dan speed terbaik dari setiap tools yang digunakan, dengan menggunakan OCR.net didapat akurasi sebesar $90 \%$ dengan speed 8 detik untuk setiap dokumen dengan menggunakan OCR.net versi desktop yang menggunakan satu GPU RTX 960 dan memory sebesar 2GB. Dan didapat akurasi sebesar $95 \%$ dengan speed 5 detik untuk setiap dokumennya untuk penggunaan tools Google Vision, dengan menggunakan satu GPU NVIDIA TESLA K80 dan memory sebesar 4GB.

\section{PERANCANGAN}

Pada bagian ini akan dibahas mengenai perancangan yang disusun untuk membuat sistem scanning. Yang mana akan dibahas mulai dari dataset yang ada, grouping dataset 
untuk mengelompokan dataset yang berbeda, image labeling untuk memberikan identitas unik pada gambar, pembuatan model CNN di mana akan dibuat dua model dengan arsitektur yang berbeda, image prediction untuk memberikan prediksi menggunakan model yang dipilih dan document scanning untuk mengambil informasi character alphanumeric dari gambar lalu akan dilakukan proses transformasi menjadi format JSON. Bagan penelitian bisa dilihat pada Gambar 5.

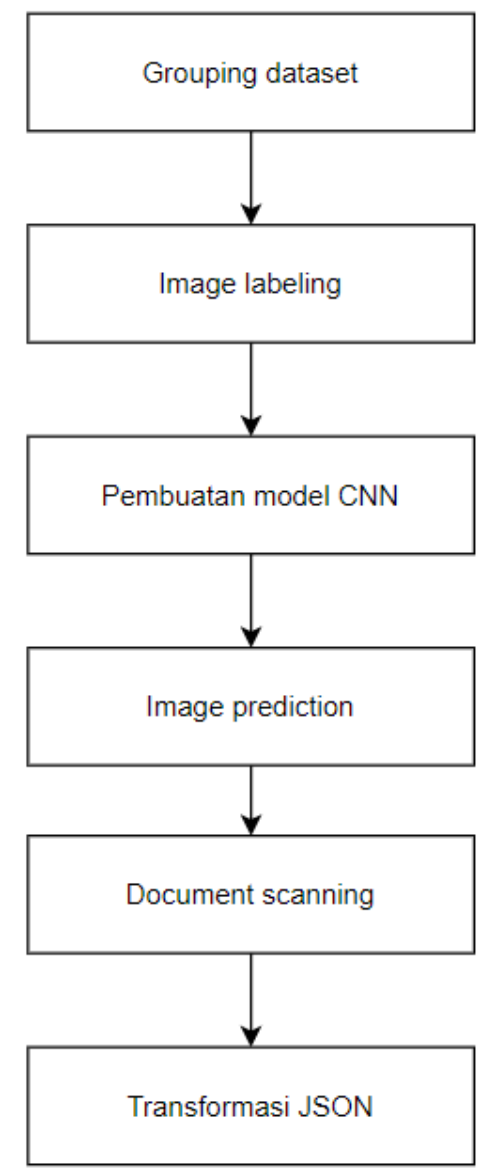

Gambar 5 Perancangan system.

\section{A. Basic Data}

Pada penelitian ini digunakan dua buah dataset form yang berbeda yaitu dataset NIST dan dataset TOBACO. Penggunaan dataset menggunakan lebih dari satu sumber dikarenakan perlu adanya keberagaman jenis form yang diharapkan bisa menjadi landasan yang baik dari model yang akan dibuat. Kedua dataset ini memiliki struktur yang berbeda di mana pada dataset NIST form yang ada akan tersebar secara random pada folder-folder yang ada, sedangkan dataset TOBACO sudah tersusun dalam direktori yang mewakilinya. Pada tahapan selanjutnya perlu dilakukan generalisasi agar kedua dataset memiliki value yang sama. Untuk contoh form bisa dilihat pada Gambar 6.

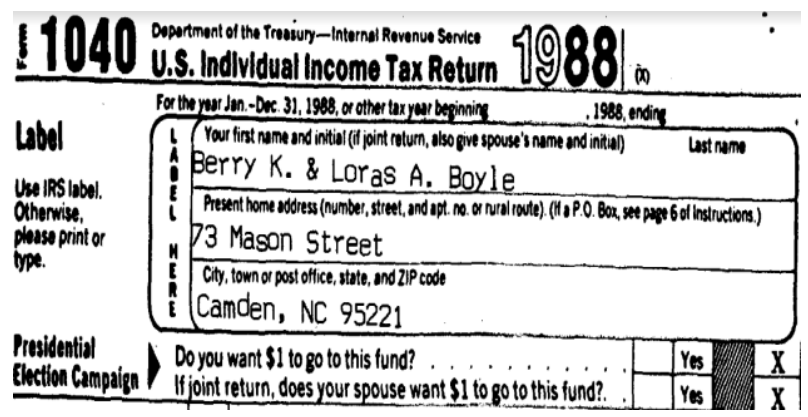

Gambar 6 Contoh Form.

\section{$B$. Pengelompokan dan pelabelan}

Langkah awal yang perlu dilakukan pada bagian ini adalah melakukan grouping dari kedua dataset yang ada Adapun perancangan yang diinginkan adalah dengan mengambil 2 jenis form dari dataset NIST yang nantinya akan digabungkan ke dalam dataset TOBACO. Sesudah grouping maka tahapan selanjutnya adalah melakukan proses labeling.

Proses labeling disini dimaksudkan untuk memberikan identitas unik kepada setiap image yang ada, teknik yang akan digunakan untuk memberikan label adalah teknik hot encode di mana setiap image akan diberikan satu buah label yang mewakili seluruh isi konten yang ada di dalam sebuah image.

Teknik hot encode ini memiliki kelebihan dibandingkan pemberian label yang biasa menggunakan bounding box, di mana proses yang dihasilkan akan jauh lebih cepat namun di sisi lain teknik ini memiliki kekurangan. Di mana proses pelabelan menggunakan nama folder sebagai key bisa mempengaruhi performa training pada tahapan pembuatan model berbasiskan $C N N$, dan juga teknik ini hanya bisa digunakan untuk keperluan yang tidak memerlukan multi label dalam sebuah image yang sama.

\section{Pembuatan Model CNN}

Tahapan selanjutnya setelah proses Hot Encode selesai adalah melakukan pemilahan data untuk dipisahkan menjadi tiga bagian yang berbeda yaitu data training, data validation dan data test. Data training memiliki fungsi sebagai data yang digunakan oleh algoritma CNN untuk membangun pemodelan yang diinginkan, data validation digunakan untuk melakukan cross check terhadap model yang dibangun untuk mengetahui tingkat akurasi model saat dilakukan cross check dengan data validation. Dan data test digunakan untuk menguji akurasi model yang sudah selesai training untuk melakukan prediksi terhadap data yang benar - benar tidak digunakan sama sekali pada saat pembuatan model. Adapun pembagian data untuk per masing - masing kategori adalah data training $70 \%$, data validation $20 \%$ dan data test $10 \%$.

Sesudah proses pembagian data selesai dijalankan maka tahapan selanjutnya yang dilakukan adalah melakukan 
proses training model. Proses training dijalankan menggunakan Algoritma CNN dengan dua jenis arsitektur yang berbeda yaitu VGG-16 dan Exception Adapun ada beberapa variable global yang sudah diset sebelumnya agar saat melakukan perbandingan, kedua arsitektur memiliki bobot yang seimbang.

Setelah model selesai dibuat maka tahapan selanjutnya adalah melakukan prediksi model. Prediksi model disini bertujuan untuk mengetahui apakah pemodelan yang dibentuk mampu memberikan prediksi secara tepat terhadap data test. Pengecekan ketepatan cukup sederhana di mana akan dibandingkan hasil prediksi dari model yang ada dengan label awal dari image, jika sesuai maka akan menghasilkan nilai positif dan jika berbeda maka akan menghasilkan nilai negatif.

\section{Document Scanning dan transformasi}

Tahapan selanjutnya setelah model yang dihasilkan bisa memberikan prediksi adalah melakukan document scanning, pada tahap ini setiap prediksi yang memiliki nilai positif akan dilakukan proses scanning menggunakan OCR. Di mana setiap karakter yang ada di dalam gambar akan ditransformasi menjadi bentuk ASCII. Namun sebelum dilakukan proses scanning, dokumen terkait akan dilakukan transformasi menjadi grayscale dan threshold. Tujuan dari transformasi ini untuk meningkatkan akurasi pembacaan dari algoritma $O C R$ itu sendiri.

Sesudah image diubah ke dalam bentuk threshold maka langkah selanjutnya adalah menerapkan algoritma $O C R$ untuk melakukan scanning dokumen yang dimaksud. Hasil scan yang dimaksud lalu akan dikonversi menjadi format JSON.

\section{HASIL PENELITIAN}

Dalam studi ini akan dilakukan pengerjaan sesuai dengan alur yang sudah dijabarkan pada bagian perancangan. Adapun akan digunakan teknik - teknik seperti hot encode, OpenCV, CNN, dan OCR untuk mendapatkan hasil dari studi ini.

Tahap awal adalah melakukan penggabungan dataset NIST dan dataset TOBACO, adapun alasan penggabungan dataset adalah untuk mendapatkan keberagaman form yang lebih unik. Di mana pertama dilakukan analisa terhadap dataset NIST yang memiliki image yang tersebar ke dalam direktori - direktori. Image yang ada di dalam direktori ini tidak menunjukan keseragaman sehingga perlu dilakukan pengelompokan lebih lanjut agar satu direktori mewakili keseragaman image.

Dataset NIST ini memiliki sebuah pasangan file dengan format fmt yang memiliki nama sama dengan image, file fmt ini memiliki informasi ID unik yang bisa menjadi kunci untuk mengelompokan image, content file fmt ini bisa dilihat pada Gambar 7. dari informasi file fmt ini akan dilakukan pengelompokan image yang didasarkan kepada informasi key yang ada di dalam file fmt dan hasil path image akan di simpan pada array untuk proses selanjutnya.

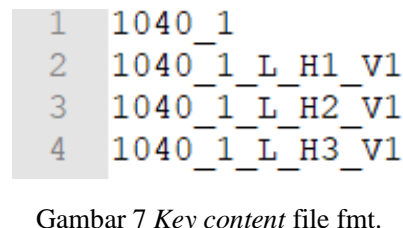

Selanjutnya adalah menggabungkan alamat yang sudah disimpan ke dalam array, ke dalam dataset TOBACO dengan cara melakukan looping array yang setiap loop nya akan melakukan cut image ke dalam direktori yang sudah ada pada dataset TOBACO. Dataset TOBACO sendiri sudah memiliki direktori - direktori yang sudah mewakili konten image yang ada di dalamnya. Adapun direktori yang sudah mewakili konten image bisa dilihat pada Gambar 8 .

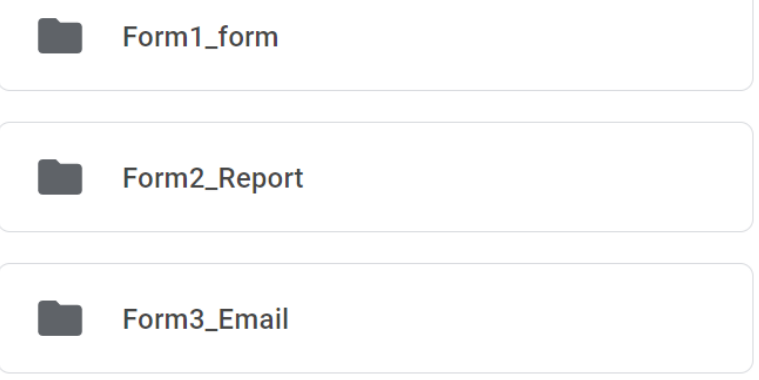

Gambar 8 Direktori hasil pengelompokan

Setelah seluruh image sudah berada di dalam direktori yang mewakili konten yang ada, tahapan selanjutnya adalah melakukan proses labeling menggunakan teknik hot encode. Teknik ini akan merubah semua image ke dalam bentuk numpy array lalu akan di sisipkan id yang merupakan nama parent direktori sebagai penanda unik suatu image.

Prinsip yang diterapkan adalah melakukan looping semua image yang ada di dalam direktori. Lalu melakukan identifikasi dengan cara membandingkan direktori image dengan kondisi penentuan label. Simulasi pemberian kondisi bisa dilihat pada Tabel I.

TABEL I

SIMULASI PEMBERIAN LABEL.

\begin{tabular}{|c|c|c|c|}
\hline Gambar & Form1 & Form 2 & Form 3 \\
\hline gambar 1 & 1 & 0 & 0 \\
\hline gambar 2 & 0 & 1 & 0 \\
\hline gambar 3 & 0 & 0 & 1 \\
\hline gambar 4 & 0 & 1 & 0 \\
\hline gambar 5 & 1 & 0 & 0 \\
\hline
\end{tabular}


Nilai 1 menunjukan bahwa image yang diproses memiliki nama direktori yang sesuai dengan kondisi penentuan label. Saat didapat nilai 1 maka sistem akan memodifikasi numpy array image dengan menambahkan informasi label sebelum dikonversi kembali menjadi image semula. Jika didapat nilai 0 menunjukan direktori image tidak sesuai dengan kondisi penentuan label dan sistem tidak melakukan action apapun.

Setelah proses pemberian label selesai dilakukan, maka tahapan selanjutnya melakukan analisa data yang ada. Gabungan kedua dataset ini memiliki jumlah image sebanyak 1400 image. Adapun seluruh image ini tersebar pada tiga buah direktori, di mana form1 berisi 444 image, form2 berisi 266 image dan form3 berisi 600 image. Yang jumlah image setiap direktorinya bisa dilihat pada Gambar 9.

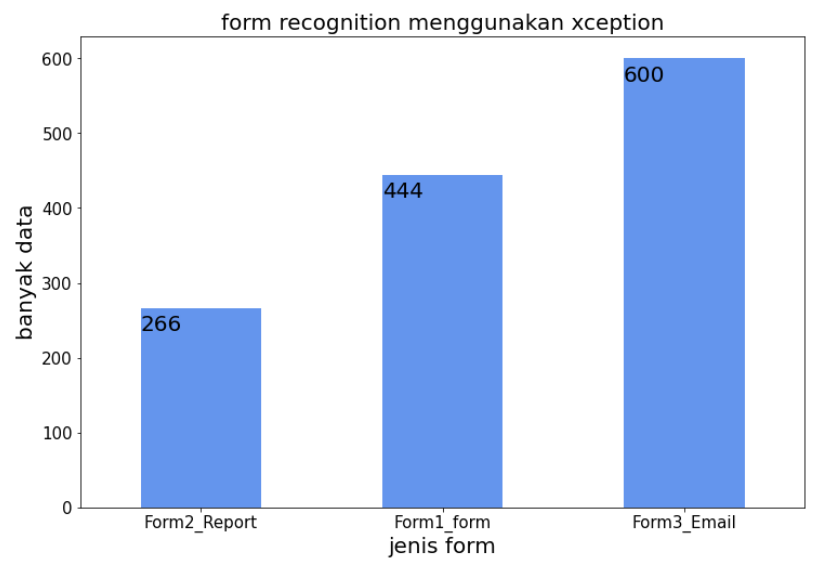

Gambar 9 Jumlah image dataset gabungan.

Sebelum melakukan proses training pemodelan CNN, perlu dilakukan setting parameter global. Hal ini dikarenakan akan dibuat dua buah model CNN yang menggunakan arsitektur yang berbeda, sehingga perlu parameter yang membuat kedua model bisa dibandingkan dengan kondisi yang sama. Informasi parameter ini bisa dilihat pada Tabel II.

TABEL II

PARAMETER GLOBAL

\begin{tabular}{|c|c|}
\hline parameter & value \\
\hline img_size & 125 \\
\hline batch_size & 32 \\
\hline epochs & 15 \\
\hline train_size & 0.7 \\
\hline val_size & 0.2 \\
\hline test_size & 0.1 \\
\hline seed & 4321 \\
\hline
\end{tabular}

Berdasarkan Tabel II nilai epoch yang di ambil adalah 15 dikarenakan pola training $C N N$ tidak difokuskan pada konten detail yang ada di dalam image, tetapi lebih berfokus pada pola dari konten image. Sehingga tidak diperlukan jumlah epoch yang tinggi untuk mencapai nilai akurasi yang stabil. Sedangkan nilai seed dimaksudkan agar kondisi random pada layer $C N N$ arsitektur yang dijalankan memiliki nilai yang sama sehingga tidak perlu dilakukan proses cross validation untuk mendapatkan nilai akurasi yang dijalankan dengan kondisi random jika tujuannya hanya untuk menentukan pemilihan model. Nilai dari seed 4321 hanya menunjukan id booking untuk kondisi training pada arsitektur yang dijalankan.

Langkah berikutnya adalah melakukan pemisahan data sesuai parameter pada Tabel II. Di mana data training sebanyak $70 \%$, data validation sebanyak $20 \%$ dan data test sebanyak $10 \%$, flow proses pemisahan data ini bisa dilihat pada Gambar 10. Proses pembagian image ini didasarkan pada jumlah keseluruhan setiap kategori form sehingga setiap segment akan memiliki perbandingan yang sama dengan kondisi perbandingan awal image seperti gambar Gambar 9 Setelah pemisahan data dilakukan maka dilakukan preprocessing convert dan resize.

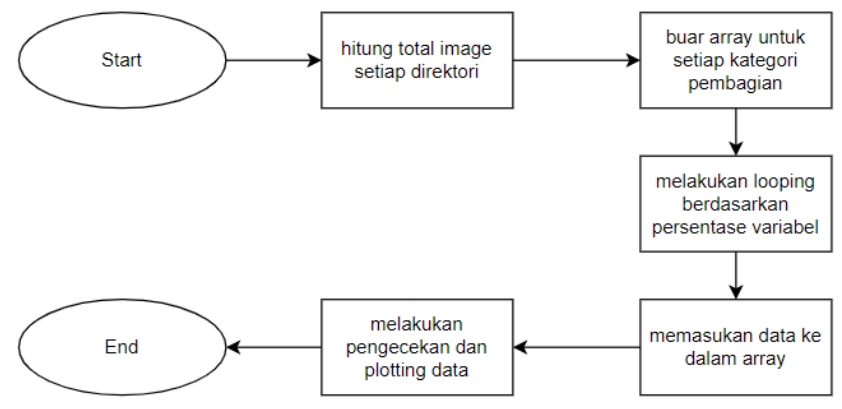

Gambar 10 Flow pembagian dataset.

Convert dibutuhkan untuk merubah format gambar untuk disesuaikan, proses convert dimaksudkan untuk merubah format gambar yang sebelumnya memiliki tiga layer $R G B$ menjadi tiga layer grayscale, tujuan proses ini untuk mempercepat proses training model yang nanti akan dilakukan. Sedangkan Rezise dilakukan untuk memperkecil ukuran gambar selain untuk mempercepat, training CNN tidak perlu mengetahui seluruh detail gambar cukup pola gambar yang bisa diidentifikasi.

Tahapan selanjutnya yang dilakukan adalah melakukan training model menggunakan $C N N$, ada dua arsitektur yang digunakan pada tahapan ini yaitu $V G G-16$ dan Exception. Dilakukan training model VGG-16 seperti Kode program 1. Model VGG-16 ini memiliki tingkat akurasi dan loss yang baik untuk 15 epoch yang dijalankan. Akurasi model $V G G$ 16 bisa dilihat pada Gambar 11, sedangkan tingkat loss model VGG-16 bisa dilihat pada Gambar 12. 


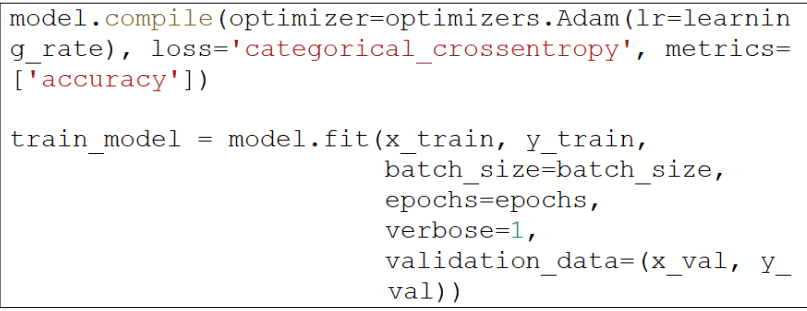

Kode program 1 Pembuatan model VGG-16.

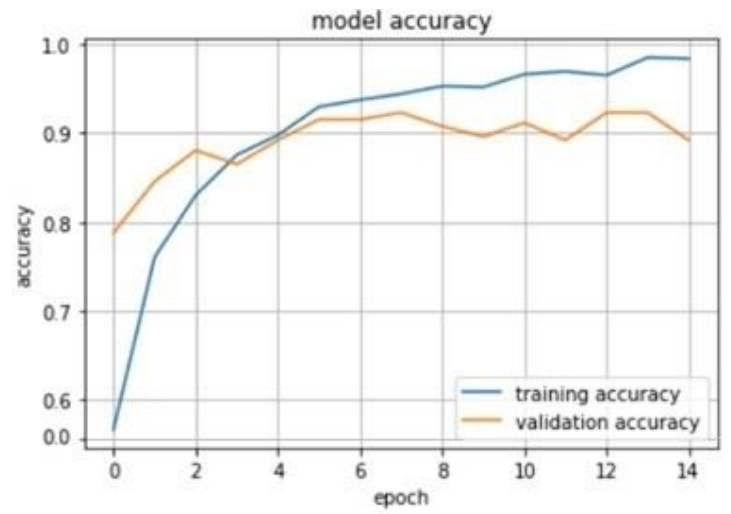

Gambar 11 Akurasi model VGG-16.

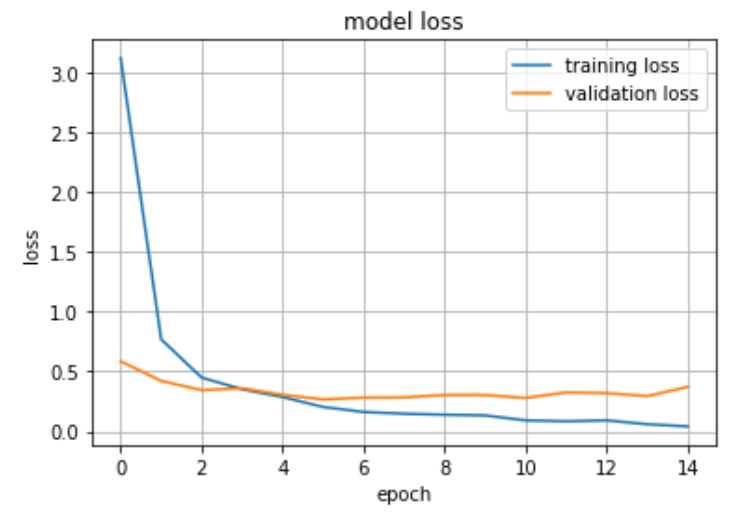

Gambar 12 Loss model VGG-16.

Sesudah Pemodelan VGG-16 selesai dibuat, maka yang dikerjakan berikutnya adalah membuat pemodelan Exception. Pembuatan pemodelan Exception bisa dilihat pada Kode program 2, model ini menghasilkan akurasi seperti yang sedikit lebih kecil dibandingkan dengan akurasi pemodelan VGG-16 seperti Gambar 13.

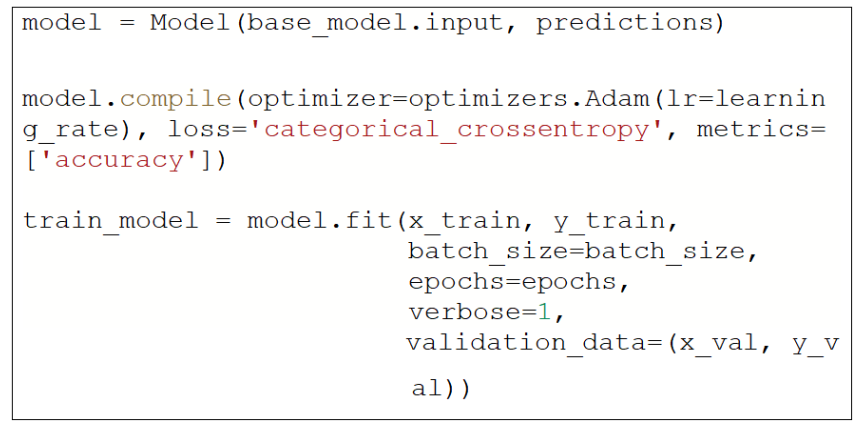

Kode program 2 Pembuatan model Exception.

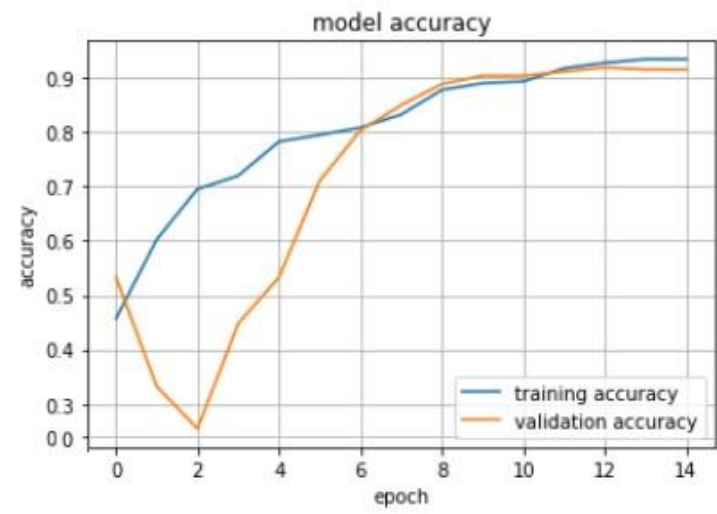

Gambar 13 Akurasi model Exception.

Ada hal yang unik pada akurasi pemodelan Exception, di mana akurasi validasi menurun di awal epoch. Hal ini dikarenakan pemodelan Exception memiliki dua buah convolutional layer, kedua layer ini akan melakukan kalkulasi secara independen saat melakukan ekstrasi fitur dalam sebuah gambar. Hal ini menyebabkan turunnya nilai loss validation yang cukup signifikan di awal epoch, namun akan meningkat saat kalkulasi kedua layer mulai menunjukan nilai yang identik. Prinsip kerja ini mirip dengan transfer learning yang terjadi di antara dua model yang berbeda, dalam kasus ini prinsip yang sama diterapkan dalam satu model yang sama.

Pemodelan Exception menghasilkan tingkat kalkulasi loss per epoch yang lebih rendah dibandingkan pemodelan $V G G$ 16 yang bisa dilihat pada Gambar 14. Hal ini dikarenakan perhitungan rumit dari dua buah convolutional layer yang bisa meningkatkan kemampuan model dalam memaksimalkan pemanfaatan fitur dalam sebuah image. 


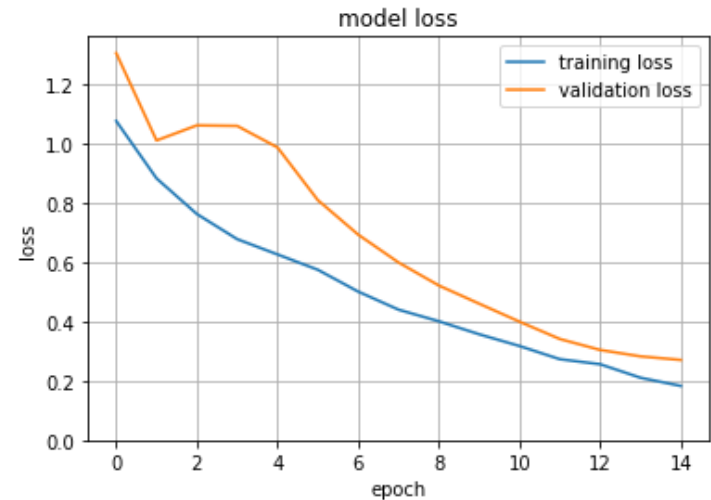

Gambar 14 Loss model Exception.

Setelah kedua arsitektur $C N N$ ini selesai dibangun maka tahapan selanjutnya adalah melakukan perhitungan akurasi dan loss secara keseluruhan untuk pemodelan Exception dan VGG-16. Pemodelan VGG-16 memiliki tingkat loss sebanyak $0.40 \%$ dan akurasi sebesar $93 \%$, sedangkan untuk pemodelan Exception memiliki tingkat akurasi sebesar $90 \%$ dan tingkat loss sebesar $0.33 \%$ yang bisa dilihat pada Tabel III.

TABEL III

PERBANDINGAN ACCURACY DAN LOSS

\begin{tabular}{|c|c|c|}
\hline Arsitektur & Accuracy & Loss \\
\hline VGG-16 & $93 \%$ & $0.40 \%$ \\
\hline Exception & $90 \%$ & $0.33 \%$ \\
\hline
\end{tabular}

Setelah mengetahui tingkat akurasi dan loss dari setiap model yang ada. Dipilih penggunaan model Exception untuk melakukan prediksi Form. Hal ini dikarenakan tingkat loss yang lebih kecil dibandingkan pemodelan VGG-16 yang menyebabkan validitas prediksi pemodelan Exception bisa lebih dipercaya, meskipun nilai akurasi pemodelan Exception lebih kecil namun masih berada dalam tingkat akurasi yang diperbolehkan, di mana akurasi sebesar $89 \%$ tidak berada dalam jangkauan overfitting ataupun underfitting sehingga model ini bisa digunakan untuk data form yang sifatnya universal. Langkah selanjutnya adalah melakukan prediksi menggunakan pemodelan Exception yang bisa dilihat pada Kode program 3 .

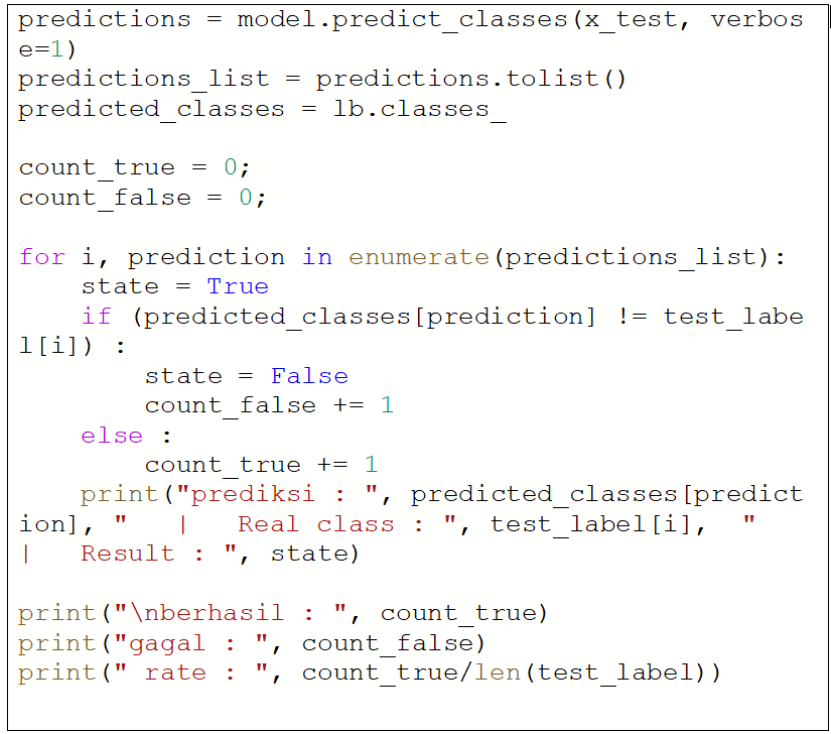

Kode program 3 Prediksi model.

Prediksi ini dilakukan oleh model terhadap data test, yang mana data ini tidak digunakan sama sekali dalam proses pembuatan model dan juga validasi. Di dapat informasi tingkat akurasi prediksi dari model Exception bisa memberikan akurasi prediksi tepat sebesar 90\% seperti Tabel IV. Kolom prediksi menunjukan hasil prediksi model terhadap data yang ada di dalam dataset, kolom real class menunjukan label yang diberikan pada image pada proses labeling yang menunjukan kategori sebuah image. Sedangkan kolom Result menunjukan hasil prediksi, jika bernilai True menunjukan bahwa nilai prediksi sama dengan nilai real class. Sedangkan jika bernilai False menunjukan nilai prediksi berbeda dengan nilai real class.

TABEL IV

HASIL PREDIKSI TERHADAP DATA TEST

\begin{tabular}{|l|l|l|}
\hline \multicolumn{1}{|c|}{ Prediksi } & \multicolumn{1}{c|}{ Real Class } & \multicolumn{1}{c|}{ Result } \\
\hline Form1_form & Form1_form & TRUE \\
\hline Form2_report & Form2_report & TRUE \\
\hline Form1_form & Form1_form & TRUE \\
\hline Form2_report & Form2_report & TRUE \\
\hline Email & Email & TRUE \\
\hline Email & Email & TRUE \\
\hline Email & Form1_form & FALSE \\
\hline Email & Email & TRUE \\
\hline Form2_report & Form2_report & TRUE \\
\hline Form1_form & Form1_form & TRUE \\
\hline
\end{tabular}


Tahap selanjutnya adalah melakukan preprocesing sebelum melakukan document scanning. Proses pertama yang dilakukan adalah transformasi gambar form menjadi format biner seperti Gambar 15. Format biner yang dimaksud adalah kondisi di mana sebuah image dikonversi menjadi gambar yang memiliki warna hitam dan putih saja, yang mana saat fitur diterjemahkan ke dalam numpy array hanya memiliki nilai 1 dan 0 . Hal ini dikarenakan $O C R$ akan lebih mudah membaca dokumen yang memiliki format biner dibandingkan $R G B$ ataupun Grayscale.

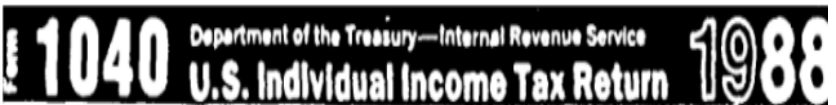

Gambar 15 Transformasi biner.

Tahap berikutnya adalah melakukan dilation. Teknik ini digunakan untuk menghilangkan garis tepi yang ada pada form yang nantinya akan dilakukan scanning yang bisa dilihat pada Kode program 4. Hal ini diperlukan agar character yang ada di dalam gambar bisa terbaca meskipun sebelumnya terkena garis tepi. Contoh perbandingan antara gambar yang masih memiliki garis tepi dan tidak bisa dilihat pada Gambar 16.

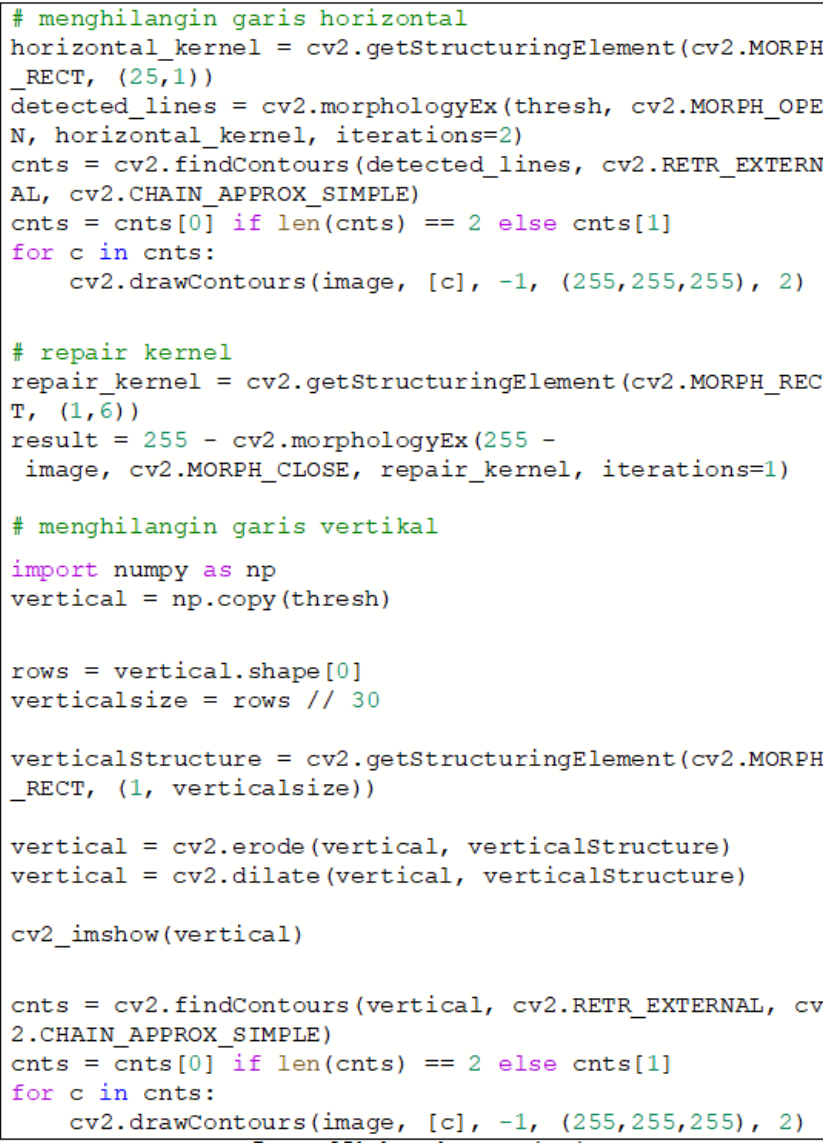

Kode program 4 Menghilangkan garis tepi.

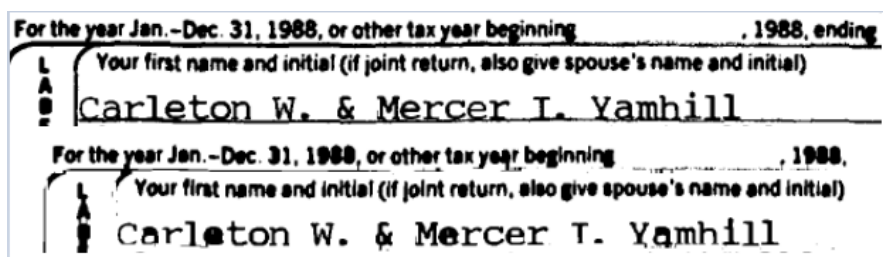

Gambar 16 Perbandingan gambar tanpa garis tepi.

Tahap selanjutnya adalah melakukan cropping untuk mengambil kolom id form, yang bisa dilihat pada Gambar 17. Meskipun pada tahapan ini scanning dokumen sudah dapat dilakukan, namun akan membutuhkan waktu yang lama untuk melakukan proses satu dokumennya dikarenakan ukuran pixel yang besar. Dengan dilakukan cropping maka akan mengurangi ukuran gambar dan meningkatkan waktu scan.

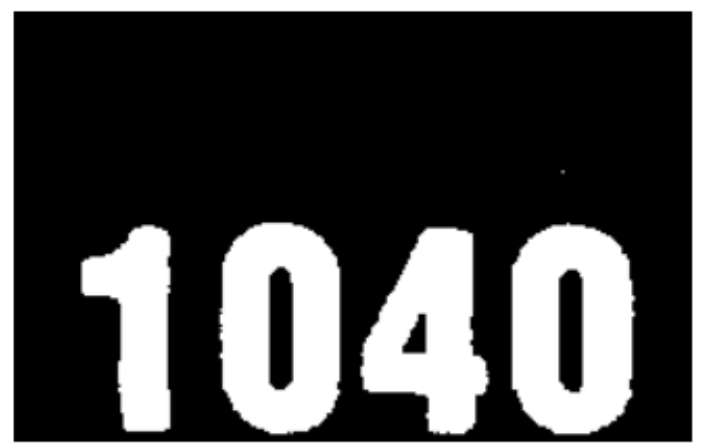

1040

Gambar 17 Crop id form.

Sesudah kolom ID form berhasil di scan dan didapat value ASCII, maka sistem akan melakukan scanning detail kolom yang ingin di ambil informasinya, contoh detail informasi form yang di scan bisa dilihat pada Gambar 18.

\section{Tulane F. and Palomar H. Norton 7 Boyle Avenue \\ Tripp, SC 92033}

Gambar 18 Detail informasi form yang di ambil.

Langkah akhir yang perlu dilakukan adalah melakukan transformasi seluruh data yang sudah di scan menjadi format JSON yang bisa dilihat pada Kode program 5, adapun format JSON yang dihasilkan bisa dilihat pada Gambar 19. 


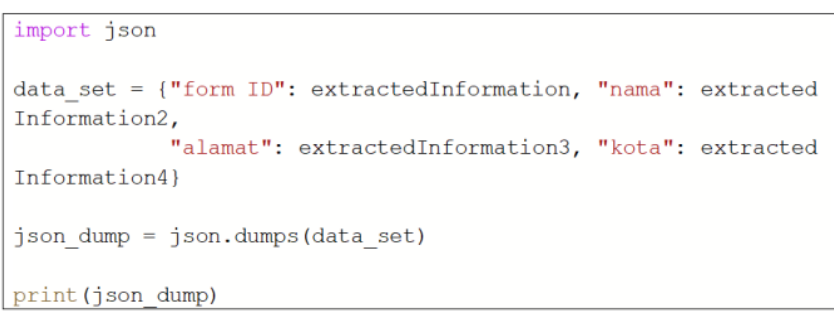

Kode program 5 Transformasi JSON.

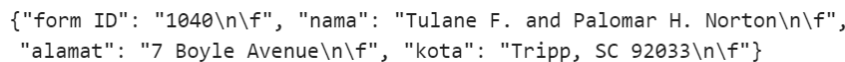

Gambar 19 Format JSON yang dihasilkan.

\section{SIMPULAN}

Sesuai dengan hasil pada Tabel IV mengenai prediksi kategori form dan Gambar 19 untuk format JSON yang digunakan, dapat disimpulkan jika sistem yang dibuat pada studi ini berhasil untuk melakukan pengkategorian form dan scanning dokumen. Pengguna tidak perlu lagi melakukan pemindahan dan pengkategorian form namun lebih kepada melakukan analisis dan perbaikan jika ada proses prediksi ataupun hasil scanning yang tidak sesuai. Sistem ini bukan produk final yang bisa langsung digunakan oleh perusahaan textile, perlu dilakukan penyesuaian dan perencanaan yang baik untuk dapat mengaplikasikan blueprint ini menjadi sebuah sistem yang utuh untuk suatu perusahaan.

\section{DAFTAR PUSTAKA}

[1] Wichian Premchaiswadi, Phaisarn, Nuchree, "The Fast Scheme for Document Page Segmentation in OCR using Window and Optimum Image," International Journal of Advanced Research in Computer Science., vol. 35, pp. 350-355, Feb. 2006.

[2] Mosalam K, Gao Y, "Deep Transfer Learning for Image-Based," Journal of Computer-Aided Civil and Infrastructure., vol. 22, pp. 233-239, Jan. 2018.
[3] Diego R Faria, Jordan J Bird, "A Study on CNN Transfer Learning for Image Classification," conference:UKCI, 2018, paper 37, p. 125.

[4] Tridib Chakraborty, Suparna Karmakar Chowdhury Md Mizan, "Text Recognition using image processing," International Journal of Advanced Research in Computer Science., vol. 8, pp. 765-768, June. 2017.

[5] Apurva A Desai, "Gujarati handwritten numeral optical character reorganization through neural network, Pattern Recognition," Pattern Recognition., vol. 43, pp. 2582-2589, Aug. 2014.

[6] Jianxin Wu, Convolutional neural networks manual, 1st ed., Wen Tau Yih. Tianjin, China: Lei Tao, 2020.

[7] Jeff Donahue, Trevor Darrell, Jitendra Malik Ross Girshick, "Region-based Convolutional Networks for Accurate Object Detection and Segmentation," IEEE Transaction on Pattern Analysis and Machine Intelligence., vol. 38, pp. 1, Dec. 2015.

[8] Bradski. (2009) OpenCV, Open source Computer Vision library. [Online]. Tersedia: http://opencv.willowgarage.com/wiki/.

[9] Mert Onulrapl Gokalp, Kerem Kayabay, Mehmet Ali Akyol, P.Erhan Eren, Altan Kocyigit, "Big Data For Industry 4.0: A Conceptual Framework," International Journal on Computational Science and Computational Intelligence., vol. 10, pp. 431-434, Dec. 2016.

[10] Patricio Cerda, Gael Varoquaux, Balazs Kegl, "Similarity encoding for learning with dirty categorical variables," Journal of Machine Learning Research., vol. 107, pp. 634-638, Sept. 2018.

[11] Patric Wspanialy, Justin Brooks, Medhat Moussa, "An Image Labeling Tool and Agricultural Dataset for Deep Learning," Journal of Machine Learning Research., vol. 112, pp. 300-304, Apr. 2020.

[12] Manohar Karki, Qun Liu, Robert DiBiano, Saikat Basu, Supratik Mukhopadhyay, "Pixel-level Reconstruction and Classification for Noisy Handwritten Bangla Characters," International Journal on Computational Science and Computational Intelligence., vol. 14, pp. 511-516, Aug. 2018.

[13] Liu Liu, Kaile Liu, Zhengchai Cong, Jiali Zhao, Yefei Ji, Jun He, "Long Length Document Classification by Local Convolutional Feature Aggregation," Algoritms., vol. 11, pp. 109, July. 2018.

[14] Sukhvinder Singh, Surender Kumar Grewal, "Text Extraction and Character Recognition form Image using Mathematical Morphology and OCR technique," International Journal of Science and Research., vol. 7, pp. 952-955, June. 2014.

[15] Rifiana Arief, Achmad Benny Mutiara, Tubagus Maulana Kususma, Hustinawaty, "Automated Extraction of Large Scale Scanned Document Images using Google Vision OCR in Apache Hadoop Environment," International Journal of Advanced Computer Science and Application., vol. 9, pp. 112-116, Jan. 2018. 